\begin{tabular}{|c|c|c|c|}
\hline DE & \multirow[t]{4}{*}{ DE GRUYTER } & $\begin{array}{l}\text { HUNGARIAN JOURNAL OF } \\
\text { INDUSTRY AND CHEMISTRY }\end{array}$ & $\begin{array}{l}\text { HUUNGARIAN JOURNAI OIS } \\
\text { INIDUSTIRY ANID CIRIEMISTIRSY }\end{array}$ \\
\hline & & Vol. 45(2) pp. 1-7 (2017) & \\
\hline & & hjic.mk.uni-pannon.hu & \\
\hline & & DOI: 10.1515/hjic-2017-0012 & \\
\hline
\end{tabular}

\title{
METHYL-TERT-BUTYL-ETHER SYNTHESIS REACTOR MODELLING AND OPTIMIZATION USING AN ASPEN CUSTOM MODELER
}

\author{
ZEESHAN NAWAZ \\ SABIC Technology \& Innovation, PO Box 42503, Saudi Basic Industries Corporation (SABIC), \\ Riyadh, 11551, SAUDI ARABIA
}

\begin{abstract}
A pseudo-homogeneous model of methyl-tert-butyl-ether (MTBE) synthesis in a multi-tubular packed-bed reactor has been developed using an Aspen Custom Modeler (ACM) for selecting optimum operating strategies, for the maximization and enhancement of MTBE production, and isobutylene consumption, respectively. The model accounts for mass, energy and momentum balances; and the effectiveness factor is evaluated in a onedimensional pseudo-homogeneous model. The kinetic investigation contains kinetic rate expressions as given by the effectiveness factor for accounting the resistance of pellets in terms of mass and heat transfer. An activity coefficient can be used in order to systematically obtain a new steady-state solution. The model used literature-based correlations for the estimation of heat transfer coefficients. The value of the coefficient for gascoolant heat transfer can be adjusted by using a tuning coefficient in order to enrich the process data. Reasonable agreement was found between model predictions and data under similar conditions. The studies concerning model sensitivity compute the optimum temperature, pressure, feed flow rate, methanol/isobutylene ratio, heat removal rate, etc. of the reactor and suggest optimum operating conditions of the reactor.
\end{abstract}

Keywords: methyl-tert-butyl-ether (MTBE) synthesis, lead reactor, multi-tubular packed-bed, Aspen Custom Modeler (ACM), isobutylene

\section{Introduction}

Methyl-tert-butyl-ether (MTBE) is of importance among petrochemicals due to its physicochemical properties and as an additive in gasoline. It contributes to the gradual elimination of lead-based additives, increasing the octane number (as an octane booster) and serves as a volume extender [1]. It is formed by the etherification reaction of an alcohol with a tertiary olefin. Ethers are preferable over alcohols due to their lower sensitivity values, i.e. the difference between the RON (Research Octane Number) and MON (Motor Octane Number) [2]. Today, standard (Huls AG) and Ethermax are the known processes commercialized by Snamprogetti, CDTech, Universal Oil Products (UOP), Axens, Fortum, Arco, Phillips, BP-Intevep, Sinopec, Sumitomo, etc. These are similar processes to each other. In this study a Snamprogetti-lead reactor is modelled to maximize its productivity.

\section{Experimental Conditions Considered}

\subsection{Reaction Chemistry}

The following five reactions (Eqs.(1-5)) are involved in MTBE synthesis when isobutylene reacts with methanol

*Correspondence: zeeshan@sabic.com
$(\mathrm{MeOH})$. MTBE synthesis is an exothermic liquidphase reversible reaction catalysed by a cationic ionexchange resin (sulphonated macroporous polystyrene). For each mole of isobutylene converted, $\sim 37.7 \mathrm{~kJ}$ of heat is released and the thermodynamic equilibrium determines the extent of conversion [1-2].

MTBE: $\mathrm{CH}_{3} \mathrm{OH}+\left(\mathrm{CH}_{3}\right)_{2} \mathrm{C}=\mathrm{CH}_{2} \leftrightarrow\left(\mathrm{CH}_{3}\right)_{3} \mathrm{COCH}_{3}$

However, undesirable side reactions may take place such as the dimerization of isobutylene to diisobutenes (DIB), 2,4,4-trimethyl-1-pentene (TMP-1) and 2,4,4trimethyl-2-pentene (TMP-2); and the formation of methyl sec-butyl ether (MSBE), dimethyl ether (DME) and tert-butyl alcohol (TBA). The water produced during the formation of DME may react with isobutylene to form tert-butyl alcohol (TBA) and its blending octane number is lower than that of MTBE. On the other hand, the presence of water reduces the acidity of the catalyst (reducing activity) and therefore a higher reaction temperature is required.

$$
\begin{array}{lc}
\text { DIB: } & 2\left(\mathrm{CH}_{3}\right)_{2} \mathrm{C}=\mathrm{CH}_{2} \leftrightarrow \\
\left(\mathrm{CH}_{3}\right)_{3} \mathrm{CH}_{2}\left(\mathrm{CH}_{3}\right) \mathrm{C}=\mathrm{CH}_{2}+\left(\mathrm{CH}_{3}\right)_{3} \mathrm{C}(\mathrm{H}) \mathrm{C}=\mathrm{C}\left(\mathrm{CH}_{3}\right)_{2}(2) \\
\text { MSBE: } & \mathrm{CH}_{3} \mathrm{OH}+\left(\mathrm{C}_{2} \mathrm{H}_{5}\right) \mathrm{CH}=\mathrm{CH}_{2} \leftrightarrow \\
& \mathrm{CH}_{3} \mathrm{CH}\left(\mathrm{OCH}_{3}\right)\left(\mathrm{CH}_{2} \mathrm{CH}_{3}\right) \\
\text { DME: } & 2 \mathrm{CH}_{3} \mathrm{OH} \leftrightarrow \mathrm{CH}_{3} \mathrm{OCH}_{3}+\mathrm{H}_{2} \mathrm{O} \\
\text { TBA: } & \left(\mathrm{CH}_{3}\right)_{2} \mathrm{C}=\mathrm{CH}_{2}+\mathrm{H}_{2} \mathrm{O} \leftrightarrow\left(\mathrm{CH}_{3}\right)_{3} \mathrm{COH}
\end{array}
$$




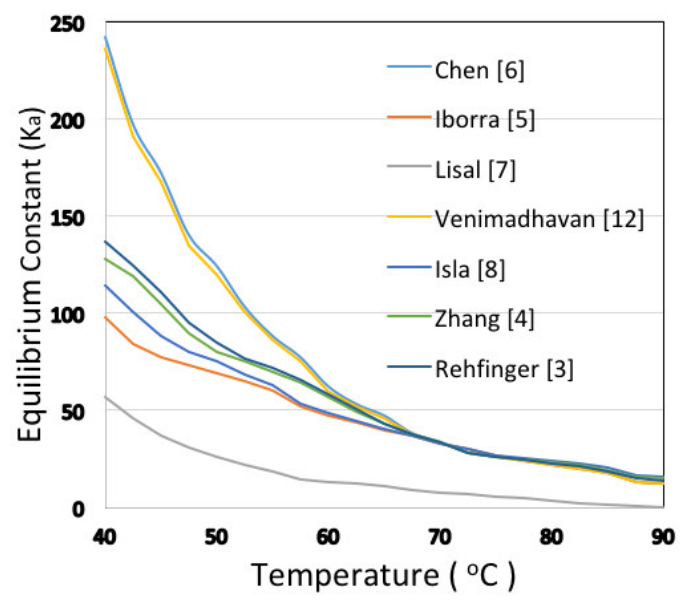

Figure 1. Values of the equilibrium constant $K_{\mathrm{a}}$ as a function of temperature.

\subsection{Thermodynamics}

Etherification is an exothermic equilibrium reaction between a primary alcohol and an iso-olefin containing a double bond on a tertiary carbon atom (such as isobutene $(\mathrm{iBu})$ under the operating temperature and pressure. Owing to the non-ideality of liquid mixtures due to their disparate polarities and equilibria, the kinetic rate expressions for the synthesis of MTBE are generally given in terms of component activities. Equilibrium and rate equations based on activities were first proposed by Rehfinger et al. [3] and kinetic (including the effectiveness factor) and equilibrium data from an isothermal packed-bed reactor using the catalyst Amberlyst-15 were discussed by Zhang et al. [4]. The activity-based equilibrium constant is expressed as:

$$
K_{\mathrm{a}}=\left[\frac{a_{\mathrm{MTBE}}}{a_{\mathrm{iBu}} \cdot a_{\mathrm{MeOH}}}\right]_{\mathrm{eq} .}=\left[\frac{\gamma_{\mathrm{MTBE}}}{\gamma_{\mathrm{iBu}} \cdot \gamma_{\mathrm{MeOH}}} \cdot \frac{x_{\mathrm{MTBE}}}{x_{\mathrm{iBu}} \cdot x_{\mathrm{MeOH}}}\right]_{\mathrm{eq}} .
$$

where $a_{\mathrm{MeOH}}, a_{\mathrm{iBu}}$, and $a_{\mathrm{MTBE}}$ are the activities of methanol, isobutene, and MTBE, respectively, while $\gamma$ and $x$ are the activity coefficients and mole fractions of these components, respectively.

The values of the equilibrium constant $\left(K_{\mathrm{a}}\right)$ published in the literature vary significantly (Fig. I) as a function of temperature [3-10]. Deviations may stem from the different bases used for the evaluation of the activity coefficient as well as from the operating temperature of the reactor, for example, employing primary reactors or reactive distillation columns.

\subsection{Catalysis and Kinetics}

The acidic cation exchange macroporous resin catalysts used commercially for the synthesis of MTBE are provided by Bayer, Dow Chemical (Rohm \& Haas), Purolite, Kairui, etc. The resins are prepared by the suspension of styrene in the presence of an appropriate cross-linking agent (divinylbenzene (DVB)) for polymerization functionalized by means of sulphonation
Table 1. Properties of the catalyst Amberlyst- 15 .

\begin{aligned} & \hline Properties Specifications \\ & \hline Porosity of Catalyst $\left(\varepsilon_{\mathrm{p}}\right) 0.31-0.39 \\ &$ Tortuosity of Catalyst $(\mathrm{t}) 0.7-1.7 \\ &$ Density of catalyst $\left(\mathrm{kg} \mathrm{m}^{-3}\right) \sim 2000 \\ &$ Physical Shape spherical beads \\ & Ionic Form hydrogen \\ & Moisture Content $(\mathrm{g} / \mathrm{g} \%) \sim 50 \\ &$ Particle Size $(\mathrm{mm}) 0.3-1.5 \\ &$ Functional Group $\mathrm{RSO}_{3} \mathrm{H} \\ &$ Surface Area $\left(\mathrm{m}^{2} \mathrm{~g}^{-1}\right) \sim 45 \\ &$ Pore Diameter $(\AA) \sim 250 \\ &$ Acid Sites $\left(\mathrm{eq}\left(\mathrm{H}^{+}\right) \mathrm{kg}^{-1}\right) 4.6-5.2 \\ &$\hline\end{aligned}

with sulphuric or chlorosulphonic acid [11]. A reduction in volume of $\sim 20-30 \%$ is observed because of the shift of the resin from the hydrated form (as it is generally charged in water) to a more contracted form due to a much less polar-reacting medium (a hydrocarbon/methanol mixture). The usability of the catalyst largely depends upon the process conditions, namely the type of reactor, e.g. a reactor receiving thermal support is better than adiabatic and thermal degradation with breakage of the carbon-sulphur bond (therefore, temperatures below $130{ }^{\circ} \mathrm{C}$ are recommended) and feed impurities (cations, e.g. $\mathrm{Na}, \mathrm{Ca}$, $\mathrm{Fe}, \mathrm{Al}, \mathrm{Cr}$, Si, etc., strong N-bases like ammonia and amines, weak N-bases like acetonitrile and propionitrile, and dienes).

The rate expressions, essential kinetic parameters and thermodynamic data such as the activation energy, effectiveness of the catalyst, heat of reaction, equilibrium constant and so forth have been selected from the literature [3-14]. The rate of reaction depends substantially on two parameters: acidity (type and number of acidic sites) and accessibility (porosity, content, particle diameter and treating medium). In the homogeneous model (in the absence of the diffusion phenomena), the reaction rate can be described in terms of confined catalyst pores, where the reactant concentration is in a partition equilibrium with the corresponding concentrations in the external solution. The rate-determining step was estimated to be the surface reaction between protonated adsorbed methanol and isobutylene [3-13]. This simplifies the rate of consumption for isobutylene after assuming that polar methanol molecules are preferentially adsorbed onto the ion-exchange resin catalyst (Table 1) and the fraction of unoccupied sites over the catalyst surface was small as follows [4]:

$$
-r_{\mathrm{iBu}}=a_{0} \cdot e^{-\frac{E_{\mathrm{a}}}{R T}} \cdot\left(\frac{a_{\mathrm{iBu}}}{a_{\mathrm{MeOH}}}-\frac{1}{K_{\mathrm{a}}} \cdot \frac{a_{\mathrm{MTBE}}}{a_{\mathrm{MeOH}}^{2}}\right)
$$

where $r_{\mathrm{iBu}}$ is the rate constant of the reaction, $R$ is the universal gas constant, $E_{\mathrm{a}}$ is the activation energy of $85.4 \mathrm{~kJ} \mathrm{~mol}^{-1}$ (for Amberlyst-15 this value varies between 71 and $93 \mathrm{~kJ} \mathrm{~mol}^{-1}$ and is influenced by not 
Table 2. Specifications of the reactor system.

\begin{tabular}{rll}
\hline Specification & Units & Value \\
\hline Reactor Length & $\mathrm{m}$ & $\sim 8$ \\
Reactor Diameter & $\mathrm{m}$ & $\sim 3.5$ \\
LHSV & $\mathrm{h}^{-1}$ & $\sim 2-9$ \\
Porosity & - & $\sim 0.35$ \\
Feed Inlet Temperature & ${ }^{\circ} \mathrm{C}$ & $\sim 40$ \\
i-C $/$ MeOH Ratio & molar & $\sim 1.1$ \\
Pressure & bar & $\sim 10$ \\
Recycling Ratio & $\%$ & $\sim 15$ \\
\hline
\end{tabular}

only the type of catalyst but also by the composition of the reaction mixture); and $a_{0}=6.3 \times 10^{12} \mathrm{~mol} \mathrm{~h}^{-1} \mathrm{~g}^{-1}$.

The effective diffusion coefficient and activation energy of methanol over Amberlyst- 15 at $60{ }^{\circ} \mathrm{C}$ was estimated to be $2.3 \cdot 10^{-9} \mathrm{~m}^{2} \mathrm{~s}^{-1}$ and $\sim 35.4 \mathrm{~kJ} \mathrm{~mol}^{-1}$, respectively [4]. The given value of the effective diffusion coefficient is slightly lower than the one Rehfinger and Hoffmann reported $\left(3.5 \cdot 10^{-9} \mathrm{~m}^{2} \mathrm{~s}^{-1}\right)$ [3]. The catalysts Kastel CS 381 and Amberlyst CSP used in the synthesis of MTBE possess similar rate constants to Amberlyst-15, whereas Amberlyst XE 307 and Duolite ES 276 have significantly higher; and Duolite C16P and Duolite C26 have substantially lower values for their rate constants [3-15]. Every resin undergoes deactivation, if sodium ions are exchanged for their protons. Due to the acidic nature of resins, the activity is strongly reduced by the presence of basic substances and/or salts in the reaction mixture. The heat of reaction, $\Delta H^{\circ}(\mathrm{MTBE})$, in the liquid phase at $25^{\circ} \mathrm{C}$ was reviewed by Iborra et al. and found to be within the range of -34 to $-40 \mathrm{~kJ} \mathrm{~mol}^{-1}$ [5].

The rate for dimerization of isobutene (DIB formation) $[4,10]$ can be calculated as follows:

$$
r_{\mathrm{DIB}}=k_{0} \cdot e^{\frac{-66.7 \mathrm{~kJ} / \mathrm{mol}}{R}} \cdot\left(\frac{1}{T}-\frac{1}{333}\right) \cdot \frac{a_{\mathrm{iBu}}^{2}}{K_{\mathrm{ad}} \cdot a_{\mathrm{MeOH}}+a_{\mathrm{iBu}}}
$$

where the unit of $r_{\mathrm{DIB}}$ is $\mathrm{mmol} \mathrm{s}^{-1} \mathrm{eq}^{-1}, K_{\mathrm{ad}}$ is the ratio of adsorption equilibrium constants, and $k_{0}$ is the frequency factor of the kinetic constant.

\subsection{Reactor and Process}

Generally, the multi-tubular packed-bed reactor is used exclusively as a front-end for the reactor performing the synthesis of MTBE, where the catalyst is lodged in the tubes $(\sim 10,000$ tubes of diameter $\sim 30 \mathrm{~mm}$, length $\sim 6 \mathrm{~m}$, $\varepsilon=0.4)$. The cooling water flows in the shell side and can either flow co- or counter-current. The reactor column is used solely for finishing and exploits the principle of catalytic distillation possessing the normal fractionation trays with reactive trays (where the catalyst is packed) $[2,16]$. Therefore, the maximum degree of isobutene conversion was achieved and reactants were separated from the product simultaneously, as MTBE has a much higher boiling temperature. Reactor parameters used for the modelling are given in Table 2. Almost all the commercial etherification technologies use similar sections with regard to operation and separation, but are different in terms of type of reactors, numbers and process schemes [16-17]. The MTBE plant consists of a multi-tubular packed-bed reactor, and reactive distillation and methanol recovery sections. There are two separation towers after each reactor that recover the $\mathrm{C}_{4} /$ methanol azeotrope from the top and MTBE from the bottom, followed by the washing tower where water removes the methanol from the $\mathrm{C}_{4}$, and then a distillation tower to separate water and methanol.

\section{Reactor Modelling}

Classical models of multi-tubular packed-bed reactors (pseudo-homogeneous one-dimensional) have been extensively discussed in the literature [1,3-5]. In this study, a custom model of an MTBE water-cooled multitubular packed-bed reactor was built using an Aspenbased platform (ACM) with the ultimate objective of developing a complete process flow-sheet using the same method as in Refs. [18-19]. Model equations have been developed based on the following assumptions:

- steady-state operation;

- plug flow with no axial mixing;

- one dimensional as no temperature and composition gradients exist in a radial direction (perfect radial mixing);

- pseudo-homogeneous conditions for fluid - solid phase interactions: transport limitations in terms of catalyst particles are taken into account by using the concept of an effectiveness factor;

- heat transfer coefficient of the liquid phase to coolant (constant value along the reactor axis) is implemented as a sub-model. The heat transfer coefficient was evaluated under various changeable process parameters as defined the coolant inlet temperature, inlet flow rate, inlet pressure and inlet composition;

- pressure drops according to the Ergun equation in the model.

\subsection{Mass and Energy Balance}

The steady-state material balance in the liquid phase expressed in terms of vectors of the molar flow rates of the components in $z$ direction is

$$
\frac{\mathrm{d} \mathbf{f}}{\mathrm{d} z}=A \mathbf{r} \quad \text { and } \quad \mathbf{r}=\rho_{\mathrm{b}} \cdot \mathbf{S}^{\mathrm{T}} \cdot \mathbf{r}_{\mathrm{kef}}
$$

where $\mathbf{r}$ is the vector of the rate of production or consumption per unit volume of a component, $\mathbf{S}$ is the stoichiometric matrix, $\mathbf{r}_{\text {kef }}$ is the vector of effective reaction rates, $A$ is the cross-sectional area of the reactor, $\mathbf{f}$ is a molar flow rate vector of the component, and $\rho_{b}$ the bulk density of the catalyst.

The liquid side of the heat balance equation under steady-state conditions is as follows: 




Figure 2. Effectiveness factor for the MTBE synthesis reaction based on data from Ref. [4].

$$
\frac{d T}{d z}=\frac{\left|\left(\Delta \mathbf{h}_{\mathrm{R}}\right)^{\mathrm{T}} \cdot \boldsymbol{r}_{\mathrm{kef}}\right| A-h_{\mathrm{fc}} \pi D_{\mathrm{t}}\left(T-T_{\mathrm{c}}\right)}{\mathbf{f}^{\mathrm{T}} \cdot \mathbf{c}_{\mathrm{p}}}
$$

where $\Delta \mathbf{h}_{R}$ is the vector concerning the heat of reaction, $\mathbf{c}_{\mathrm{p}}$ is the vector concerning the molar specific heat of a component, $T$ and $T_{\mathrm{c}}$ are the liquid phase and coolant absolute temperatures, respectively, $h_{\mathrm{fc}}$ is the liquid-tocoolant heat transfer coefficient, and $D_{\mathrm{t}}$ is the diameter of the reactor tube.

The shell side of the heat balance equation under steady-state conditions is as follows:

$$
\frac{d T_{\mathrm{c}}}{d z}= \pm \frac{h_{\mathrm{fc}} \cdot \pi \cdot D_{\mathrm{t}}\left(T-T_{\mathrm{c}}\right)}{F_{\mathrm{Vcool}} \cdot \rho_{\mathrm{cool}} \cdot c_{\mathrm{s}, \mathrm{cool}}}
$$

where $F_{\mathrm{Vcool}}$ is the volumetric flow rate of the coolant, $\rho_{\text {cool }}$ is the density of the coolant, and $c_{\mathrm{s}, \mathrm{cool}}$ is the specific heat capacity of the coolant. In terms of modelling, the negative sign stands for the countercurrent and the positive sign for the co-current.

The boundary conditions at the inlet of the reactor in terms of the material and energy balance differential equations are $z=0, F_{\mathrm{i}}(0)=F_{0, \mathrm{i}}, T(0)=T_{0}, T_{\mathrm{c}}(0)=T_{\text {cool, in }}$ and $T_{\mathrm{c}}\left(R_{\mathrm{L}}\right)=T_{\text {cool,in }}$.

\subsection{Effectiveness Factor}

The effectiveness factor for the synthesis of MTBE has been evaluated on the basis of data concerning the generalized Thiele modulus $\left(\phi_{\mathrm{g}}\right)[3]$ :

$$
\eta=\tanh \left(\underline{\phi}_{\mathrm{g}}\right) / \underline{\phi}_{\mathrm{g}}
$$

In terms of the pseudo-homogeneous model, the effectiveness factor is expressed as a function of temperature and conversion:

$$
\eta=\frac{1}{x_{1} \cdot e^{\frac{-x_{2}}{R T}} \cdot\left(1.1-\left(\frac{\text { conversion } \%}{100}\right)^{\mathrm{x}_{3}}+x_{4}\right)}
$$

The parameters $x_{1}-x_{4}$ have been evaluated by minimizing the absolute error between evaluations by Zhang et al. [4] and the values predicted by Eq. 13. The accuracy of the prediction is shown in Fig. 2.

\subsection{Overall Heat Transfer Coefficient}

The overall heat transfer coefficient, taking into account the small value of the wall thickness, is evaluated as follows:

$$
h_{\mathrm{fc}}=\frac{1}{\left[\frac{1}{h_{\mathrm{fw}}}+\frac{D_{\mathrm{te}}-D_{\mathrm{ti}}}{2 \cdot \lambda_{\text {pipe }}}+r_{\text {fouling }}+\frac{1}{h_{\text {shell }}}\right]}
$$

where $D_{\mathrm{ti}}$ and $D_{\mathrm{te}}$ are the internal and external diameters of the reactor tube, respectively, $\lambda_{\text {pipe }}$ is the thermal conductivity of the reactor tube, $h_{\mathrm{fw}}$ is the fluid-to-wall heat transfer coefficient, $h_{\text {shell }}$ is the shell side (wall-tocooling water) heat transfer coefficient, and $r_{\text {fouling }}$ is the fouling factor.

The evaluation of the fluid-to-wall heat transfer coefficient was conducted on the basis of a newly proposed correlation for the estimation of the total (wall and effective thermal conductivity effects) heat transfer coefficient [16]:

$$
\mathrm{Nu}_{\mathrm{f}}=\left[3.87-3.77 \cdot \exp \left(\frac{-1.37}{D_{\mathrm{ti}} / d_{\mathrm{p}}}\right) \cdot \mathrm{Re}_{\mathrm{f}}^{0.643} \cdot \operatorname{Pr}_{\mathrm{f}}^{0.333}\right]
$$

In this case, both $\mathrm{Nu}_{\mathrm{f}}$ and $\mathrm{Re}_{\mathrm{f}}$ are expressed based on particle diameters. The heat transfer coefficient of the shell side is expressed as a function of $\mathrm{Nu}$ and $\mathrm{Re}$ and are both based on the external diameter of the tube, where $\varepsilon_{\varphi}$ stands for a correction factor accounting for the angle between the coolant stream and reactor tubes:

$$
\mathrm{Nu}_{\mathrm{s}}=0.4 \cdot \varepsilon_{\phi} \cdot \operatorname{Re}_{\mathrm{s}}^{0.6} \cdot \operatorname{Pr}_{\mathrm{s}}^{0.333}
$$

\subsection{ACM Property Estimations}

The physical properties of components and mixtures like viscosity, density and specific heat, were estimated by Aspen Properties (using UNIFAC - Dortmund property package). The ".appdf" file prepared by Aspen Properties is the one called in ACM for seamless transfer of properties. The kinetic sub-model helps in terms of the calculation of reaction heats using the Aspen Properties database. 
Table 3. Typical base-case operating conditions and results for the primary reactor.

\begin{tabular}{rll}
\hline Specification & Units & Value \\
\hline tube length & $\mathrm{m}$ & 6 \\
tube diameter (ID) & $\mathrm{mm}$ & 21 \\
number of tubes & - & 10,000 \\
porosity & - & 0.33 \\
feed inlet temperature & ${ }^{\circ} \mathrm{C}$ & 50 \\
isobutene/MeOH ratio & molar & 1.1 \\
pressure & bar & 8 \\
coolant inlet temperature & ${ }^{\circ} \mathrm{C}$ & 45 \\
feed flow rate & $\mathrm{kmol} \mathrm{h}$ & 2,000 \\
isobutene mole fraction & - & 0.35 \\
$\Delta \mathrm{P}$ & $\mathrm{bar}$ & 0.723 \\
conversion & $\%$ & 84.7 \\
MTBE selectivity & $\%$ & 97.86 \\
\hline & &
\end{tabular}

\subsection{Performance Parameters}

Reactor performance is evaluated by the following equations:

$$
\begin{aligned}
& \operatorname{Conversion}(z)=\frac{F_{0}^{\text {key_reactant }}-F_{\mathrm{z}}^{\text {key__reactant }}}{F_{0}^{\text {key_reactant }}} \\
& \operatorname{Selectivity}(z)=\frac{F_{\mathrm{z}}^{\text {key_product }}-F_{0}^{\text {key_product }}}{F_{0}^{\text {key_reactant }}-F_{\mathrm{z}}^{\text {key_reactant }}} \\
& \operatorname{Yield}(z)=\operatorname{Conversion}(z) \cdot \operatorname{Selectivity}(z)
\end{aligned}
$$

where $z$ stands for the axial coordinate.

\section{Model Predictions and Analysis}

$\mathrm{ACM}$ is the preferred choice for robust reactor modelling. Its equation-oriented modelling platform can be easily exported to Aspen Plus process flow-sheets. The coding of a multi-tubular packed-bed reactor in terms of the synthesis of MTBE was conducted in a modular form. The main reactor model defines the constitutive equations in the bulk phase and sub-models

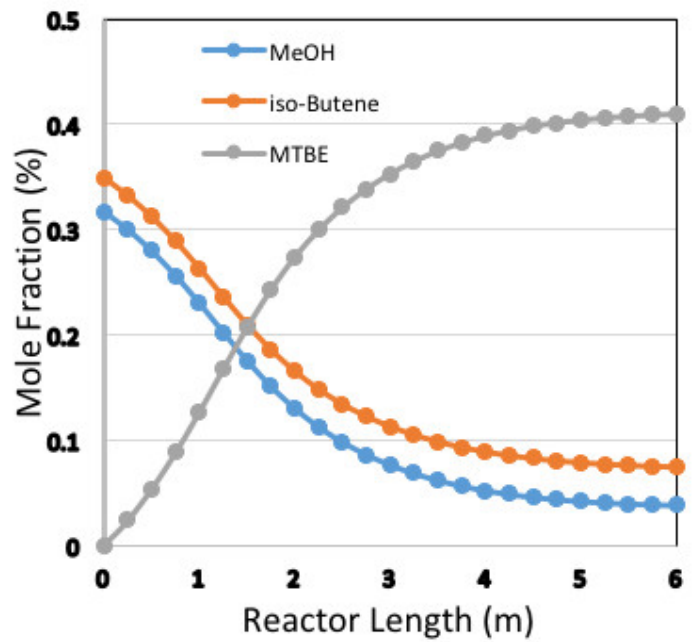

Figure 3. Molar concentration profile along the length of the reactor.

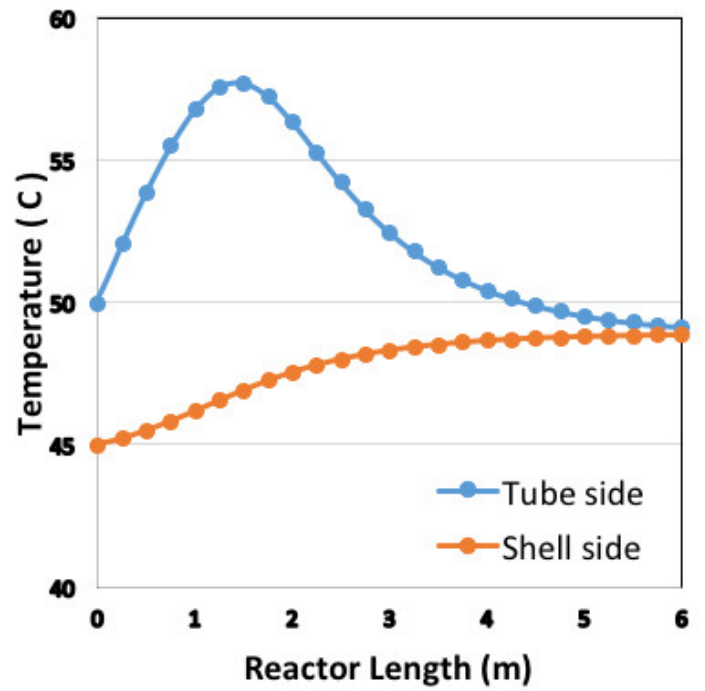

Figure 4. Temperature profiles of the reactor and coolant.

in terms of the reaction kinetics, the estimation of the heat transfer coefficient, and the development of the pellet design. The normal operating conditions for the primary reactor were selected as the base case in terms of modelling (Table 3), where MTBE productivity is $\sim 50 \mathrm{~T}^{-1}$. The molar concentration profile of the reactants and product along the axis of the reactor is shown in Fig.3. The full length of the reactor is used for the synthesis of MTBE. Fig. 4 shows the temperature profiles of the reactor and coolant.

The temperature sensitivity is controlled by keeping the temperature difference between the coolant and feed temperatures constant (Fig.5). It was observed that due to the exothermic nature of the reaction, the maximum temperature increased significantly with the

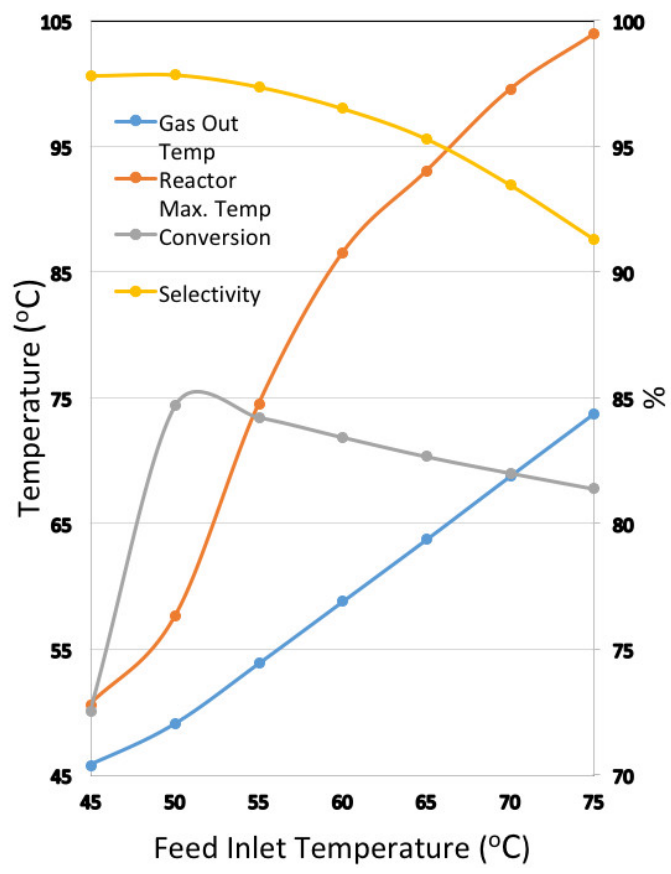

Figure 5. Temperature sensitivity by varying the feed temperature and keeping constant the temperature difference between the coolant and feed temperatures. 
Table 4. Dependence of conversion (\%), selectivity (\%) and the maximum temperature of the reactor $\left(T_{\max }\right)$ on the isobutene/methanol molar ratio $(\mathrm{iBu} / \mathrm{MeOH})$.

\begin{tabular}{lllllll}
\hline $\mathrm{iBu} / \mathrm{MeOH}$ & 0.8 & 0.9 & 1.0 & 1.1 & 1.2 & 1.3 \\
\hline conversion & 84.7 & 85.4 & 85.5 & 84.6 & 80.7 & 76.7 \\
selectivity & 98.1 & 98.1 & 98.1 & 97.9 & 97.1 & 95.4 \\
$T_{\max },{ }^{\circ} \mathrm{C}$ & 56.1 & 56.5 & 56.9 & 57.7 & 59.5 & 62.0
\end{tabular}

increase in reaction temperature. At a constant pressure and feed flow rate, the increase in the reaction temperature led to an outer mass transfer limitation that strongly affects the rate of conversion. At the same time the selectivity also decreased due to a significant increase in the maximum temperature of the reactor (product degradation) and the maximum rate of conversion was achieved in almost $\sim 30 \%$ of the reactor. The isobutylene/methanol molar ratio is one of the key operating parameters and is always kept higher than its stoichiometric value. Table 4 shows that by deviating from the stoichiometric ratio the effect on the rate of conversion and selectivity also decreases with the increase in the isobutylene/methanol molar ratio.

The predictions according to reactor modelling were found to be in good agreement with data from the literature. The reaction must reach an equilibrium at the rear end of the lead reactor. The estimated effectiveness factor is 0.75 which was also used in the model. The possible explanation for the occurrence of minor discrepancies could be the use of a different catalyst or errors in terms of experimental measurements. It was observed that the maximum degree of productivity corresponded to an isobutene $\mathrm{MeOH}$ molar ratio of close to 1 and a feed inlet temperature of between 50 and $55{ }^{\circ} \mathrm{C}$. However, it is necessary to synchronize this with the secondary reactor and other unit operations.

\section{Conclusion}

An ACM-based pseudo-homogeneous model with regard to the synthesis of MTBE using an industrial multi-tubular packed-bed (methyl-tert-butyl-ether) reactor has been developed for enhancing operation strategies. The UNIFAC - Dortmund property package was used for reactor modelling. The effectiveness factor was implemented as a function of the reaction temperature. The model was validated using data from the literature. Various sensitivity evaluations were conducted to determine the operational optimization and maximization of MTBE production under different operating parameters. The model was able to predict reaction behaviour and produce temperature and concentration profiles along the length of the reactor. Sensitivity studies were able to calculate the optimum temperature, feed flow rate, methanol/isobutylene ratio as well as heat removal rate of the reactor and thus provide insights into a reasonable operational strategy.

\section{SYMBOLS}

\begin{tabular}{|c|c|}
\hline $\begin{array}{l}A \\
a\end{array}$ & $\begin{array}{l}\text { cross-sectional area of the reactor } \\
\text { activity }\end{array}$ \\
\hline \multicolumn{2}{|c|}{$a_{\mathrm{MeOH}}, a_{\mathrm{iBu}}, a_{\mathrm{MTBE}}, a_{\mathrm{inert}}$} \\
\hline & $\begin{array}{l}\text { activities of methanol, isobutene, MTBE and } \\
\text { inert isobutane, respectively }\end{array}$ \\
\hline$a_{0}$ & $6.3 \times 10^{12} \mathrm{~mol} \mathrm{~h}^{-1} \mathrm{~g}^{-1}$ \\
\hline $\mathbf{c}_{\mathrm{p}}$ & molar specific heat vector of a component \\
\hline$c_{\mathrm{s}, \mathrm{cool}}$ & specific heat capacity of the coolant \\
\hline$D_{\mathrm{t}}$ & diameter of the reactor tube \\
\hline$D_{\mathrm{ti}}, D_{\mathrm{te}}$ & $\begin{array}{l}\text { internal and external diameters of the reactor } \\
\text { tube, respectively }\end{array}$ \\
\hline$E_{a}$ & activation energy in $\mathrm{kJ} \mathrm{mol}^{-1}$ \\
\hline$F_{\text {Vcool }}$ & volumetric flow rate of the coolant \\
\hline & molar flow rate vector of a component \\
\hline$h_{\mathrm{fc}}$ & liquid-to-coolant heat transfer coefficient \\
\hline$h_{\mathrm{fw}}$ & fluid-to-wall heat transfer coefficient \\
\hline$h_{\text {shell }}$ & $\begin{array}{l}\text { shell side (wall-to-cooling water) heat } \\
\text { transfer coefficient }\end{array}$ \\
\hline$\Delta \mathbf{h}_{\mathrm{R}}$ & heat of reaction vector \\
\hline$\gamma$ & activity coefficient \\
\hline$K_{\mathrm{a}}$ & equilibrium constant (based on activities) \\
\hline$K_{\text {ad }}$ & ratio of adsorption equilibrium constants \\
\hline \multicolumn{2}{|c|}{$K_{\mathrm{MeOH}}, K_{\mathrm{iBu}}, K_{\mathrm{MTBE}}, K_{\text {inert }}$} \\
\hline & $\begin{array}{l}\text { adsorption equilibrium constants for } \\
\text { methanol, isobutene, MTBE and inert } \\
\text { isobutane, respectively }\end{array}$ \\
\hline$k_{0}$ & frequency factor of the kinetic constant \\
\hline$k_{\mathrm{r}}$ & reaction rate constant \\
\hline$\lambda_{\text {pipe }}$ & thermal conductivity of the reactor tube \\
\hline $\mathrm{R}$ & universal gas constant \\
\hline $\mathbf{r}$ & $\begin{array}{l}\text { vector of the rate of production or } \\
\text { consumption per unit volume of a component }\end{array}$ \\
\hline $\mathbf{r}_{\mathrm{kef}}$ & vector of effective reaction rates \\
\hline$r_{\text {fouling }}$ & fouling factor \\
\hline$\rho_{\mathrm{b}}$ & bulk density of the catalyst \\
\hline$\rho_{\text {cool }}$ & density of the coolant \\
\hline $\mathbf{S}$ & stoichiometric matrix \\
\hline$T, T_{\mathrm{c}}$ & $\begin{array}{l}\text { absolute temperatures of the liquid phase and } \\
\text { coolant, respectively }\end{array}$ \\
\hline & mole fraction \\
\hline
\end{tabular}

\section{Acknowledgement}

The author gratefully acknowledges the technical support of Prof. Dr. Ing. Teodor Todinca at the University Politechenica Timisoara in Romania.

\section{REFERENCES}

[1] Nawaz, Z.: Light alkane dehydrogenation to light olefin technologies: A comprehensive review, Rev. Chem. Engng., 2015 31(5), 413-436 DOI 10.1515/revce-2015-0012 
[2] DiGirolamo, M.; Sanfilippo, D.: Etherification: Process to improve the quality of distillates, in Beccari M.; Romano, U.; eds. Encyclopaedia of hydrocarbons (ENI S.p.A and Istituto della Enciclopedia Italiana fondata da Giovanni Treccani S.p.A, Roma, Italy) 2006 Vol. II. pp. 193-209

[3] Rehfinger, A.; Hoffmann, U.: Kinetics of MTBE liquid phase synthesis catalyzed by ion-exchange resin. I. Intrinsic rate expression in liquid phase activities, Chem. Eng. Sci., 1990 45(6), 1605-1617 DOI 10.1016/0009-2509(90)80014-6

[4] Zhang, T.; Datta, R.: Integral analysis of MTBE synthesis kinetics, Ind. Eng. Chem. Res., 1995 34, 730-740 DOI 10.1021/ie00042a004

[5] Iborra, M.; Tejero, J.; Ben El-Fassi, M.; Cunill, F.; Izquierdo, J.F.; Fite, C.: Experimental study of the liquid phase simultaneous synthesis of MTBE and TBA, Ind. Eng. Chem. Res., 2002 41, 5359-5365 DOI 10.1021/ie010640q

[6] Chen, F.; Huss, R.S.; Doherty, M.F.; Malone, M.F.: Multiple steady-states in reactive distillation: kinetic effects, Comp. Chem. Engng., 2002 26, 8193 DOI 10.1016/S0098-1354(01)00750-5

[7] Lisal, M.; Smith, W.R.; Nezbeda, I.: Molecular simulation of multicomponent reaction and phase equilibria in MTBE ternary system, AIChE J., 2000 46(4), 867-875 DOI 10.1002/aic.690460419

[8] Isla, M.; Irazoqui, H.: Modeling, analysis and simulation of MTBE reactive distillation column, Ind. Eng. Chem. Res., 1996 35, 2696-2708 DOI 10.1021/ie9505930

[9] Venimadhavan, G.; Malone, M.F.; Doherty, M.F.: Bifurcation study of kinetic effects in reactive distillation, AIChE J., 1999 45(3), 546-556 DOI 10.1002/aic.690450311

[10]Oktar, N.; Murtezaoglu, K.; Dogu, T.; Dogu, G.: Dynamic analysis of adsorption equilibrium and rate parameters of reactants and products in MTBE, ETBE and TAME production, Can. J. Chem. Eng., 1999 77, 406-412 DOI 10.1002/cjce.5450770229
[11] Girolamo, M.; Tagliabue, L.: MTBE and alkylate co-production: fundamentals and operating experience, Catal. Today, 1999 52, 307-319 DOI 10.1016/S0920-5861(99)00084-X

[12] Ancilotti, F.; Fattore, V.: Oxygenate fuels: Market expansion and catalytic aspect of synthesis, Fuel Proc. Technol., 1998 57, 163-194 DOI 10.1016/S03783820(98)00081-2

[13] Girolamo, M.; Lami, M.; Marchionna, M.; Pescarollo, E.; Tagliabue, L.; Ancilotti, F.: Liquid phase etherification/dimerization of isobutene over sulfonic acid resins, Ind. Eng. Chem. Res., 1997 36, 4452-4458 DOI 10.1021/ie9700932

[14] Miracca, I.; Tagliabue, L.; Trotta, R.: Multitubular reactors for etherifications, Chem. Engng. Science, 1996 51, 2349-2358 DOI 10.1016/0009-2509(96)00091-7

[15]Panneman, H.J.; Beenackers, A.: Influence of the isobutene/methanol ratio and of the MTBE content on the reaction rate of the synthesis of MTBE, Ind. Eng. Chem. Res., 1995 34, 3817-3825 DOI 10.1021/ie00038a019

[16] Mariani, N.J.; Martinez, O.M.; Barreto, G.F.: Evaluation of heat transfer parameters in packed beds with cocurrent downflow of liquid and gas, Chem. Engng. Science, 2001 56, 5995-6001 DOI 10.1016/S0009-2509(01)00225-1

[17]Elkanzi, E.M.: Optimization of MTBE synthesis in a packed-bed reactor system, Chem. Engng. Proc., 1996 35, 131-139 DOI 10.1016/0255-2701(95)04122-2

[18]Nawaz, Z.: Dynamic modeling of CATOFIN ${ }^{\circledR}$ packed-bed isobutane dehydrogenation reactor for operational optimization, Int. J. Chem. Reactor Engng., 2016 14(1), 491-515 DOI 10.1515/ijcre-20150087

[19]Nawaz, Z.: Heterogeneous reactor modeling of an industrial multitubular packed-bed ethylene oxide reactor, Chem. Engng. Technol., 2016 39(10), 1845-1857 DOI 10.1002/ceat.201500603 